\title{
Research on the Algorithm of the Measurement Task Scheduling for the Space Launch Offshore Survey
}

\author{
Liu Jinyuan $^{1, \text { a }}$, Liao Liangcai ${ }^{1, b}$, Zhang Jie ${ }^{1, \mathrm{c}}$ and Chen Zhongyi ${ }^{1, \mathrm{~d}}$ \\ ${ }^{1}$ School of Information System and Management, National University of Defense Technology, \\ Changsha 410073, China;
}

aliujinyuan09@qq.com, bIlc_nudt@163.com, 'ben200905019025@163.com, d416259280@qq.com

Keywords: Space Launch, Offshore Survey Ship, Scheduling Algorithm.

\begin{abstract}
Space launch offshore measurement is an important part of space launch, in order to overcome the survey ship shortage for space launch tracking tasks, task scheduling method research is most needed. The space launch survey ships at sea measurement task scheduling problem described analysis to establish the survey ship scheduling mathematical model, gives two kinds of solution of scheduling algorithms that suitable for maritime space survey ship measurement task scheduling strategy, with less space tracking ship completed quantity larger space launch marine surveys, and meet cost, task goals of balancing constraints in a certain extent.
\end{abstract}

\section{Introduction}

With the further development of China's aerospace industry, China Aerospace Launching tasks appear increasing trend, especially the construction of Beidou satellite navigation system to China Aerospace mission has been faced with the challenge of a high density emission. In all aerospace measurement and control tasks, the ground-based monitoring stations and the SEF and stand together to complete the mission control, due to the spacecraft for over $60 \%$ of the orbital arc segment in the scope of the waters, to achieve full coverage, it needs the participation of offshore survey ship. Due to China's offshore aerospace survey ships ${ }^{[1]}$ (Yuanwang Series) as a relatively limited number of space launch the contradiction between demand and measurements of sea resources have become increasingly prominent. The measurements of survey ship task planning, planning is affected by the space shuttle mission plan, objectives and tasks of the waters, weather and climate, and various elements of the political environment on the target of its maritime neighbors offshore measurement cost is more and more, resource sharing, schedule conflicts have become increasingly prominent.

The mission planning of survey ship scheduling problem of spacecraft is an important link in the field of spaceflight. At present, the research on the measurement of the ship is only in the space survey ship's navigation ${ }^{[2]}$, equipment management and maintenance ${ }^{[3]}$, the measurement of the ship hull itself $^{[4]}$ as well as the impact of measurement error analysis ${ }^{[5]}$. But for aerospace survey ships at sea measurement task scheduling research still remain in the stage of artificial scheduling, related research in domestic has not carried out, so aerospace survey ships at sea measurement task scheduling research carry out has considerable practical significance and theory value.

\section{The problem description and model establishment of offshore space survey ship}

Problem Description. Space launch offshore survey ship $B_{i}$ in the implementation of the single marine surveys, from the base $M_{0}$ and according to the scheduled routes into the designated area $M_{j}$, as it arrived, the need for a certain period of time $D T_{i}$ (testing and debugging time) for measuring equipment testing and debugging. After the launch of the rocket launch, the specific time $\left(\mathrm{M}_{j} \mathrm{~TB}, \mathrm{M}_{j} \mathrm{TF}\right)$ in the specific region of the target aircraft tracking and measurement, to ensure that the target aircraft to rise, into orbit, normal operation in orbit. After the end of the task, the survey ship $B_{i}$ returned to base $M_{0}$ for maintenance and personnel necessary to rest. The single measurement 
task of the space launch offshore survey ship is: base to complete the task in the sea area survey task and go back.

Measurements of survey ship in repeatedly continuous task, just like a single task, in the designated area after the completion of the task, go directly to the next task waters task debugging, completed a measurement task. Sometimes in after the completion of the task, the need for measurement of the next task, but the survey ship supply is not enough to support the next task and returns base in time does not allow, then survey ship need stop at a foreign port supply to rest, although after then a measurement task. Marine measurement space launch many successive measurement tasks: base->task waters $->\ldots$ - > foreign port recharge $->\ldots$ - > task waters- $>$ base.

Different types of measuring instruments in the measurement of the instrument and equipment are different, the task type is not the same, different space missions may require different offshore survey ship to complete. At the same time, some important missions (such as the Shenzhou manned spacecraft launch) need to have 2 to 3 survey ships for different positions. China's current space launch is limited to the number of survey ships, only three survey ships in service and growing space launch with a finite number of measuring security contradiction, be badly in need of scientific method for measuring ship marine surveys were planning and scheduling, the in satisfying certain conditions of the successful completion to the space launch marine surveys.

Model. In field research, experts to discuss and to ensure tasks based on the basis, the maritime space survey ship was completed maritime space measurement task optimization objectives identified in the following four aspects: 1 . Sailing cost lowest; 2 . All measurement ship total time at sea at least; 3. Measurement among the ships at sea time balancing; 4 . Use survey ship with a minimum number.

$$
\text { Min } f_{1}=\sum_{i=1}^{I} \sum_{k=1}^{i k}\left(\sum_{j=1}^{n k+1}\left(L\left(M_{i j-1}, M_{i j}\right) * C_{i}\right)+\left(T F_{i 0}^{k}-T S_{i 0}^{k}\right) * C p_{i}+i k f * C f_{i}\right)
$$

In type (1), $f_{1}$ is the total cost of all ships in the annual plan, it contains three parts: one is the shipping cost, the second is the human cost, the third is to stop the foreign port cost and survey ship in performing the measurements of consumption costs not included in the cost optimization goal. $L\left(M_{i j-1}, M_{i j}\right)$ means distance between two measuring points, $C_{i}$ is boat i unit cost. $T F_{i 0}^{k}-T S_{i 0}^{k}$ means boat i single task's duration, $C p_{i}$ is the human cost per day, $i k f$ means boat i the $\mathrm{k}_{\text {th }}$ time stop at the foreign port and $C f_{i}$ is the cost at each foreign port.

$$
\begin{aligned}
& \operatorname{Min} f_{2}=\sum_{i=1}^{I} \sum_{k=1}^{i k} \sum_{j=1}^{n k+1}\left(T S_{i 0}^{k}-T F_{i 0}^{k}\right) \\
& \operatorname{Min} f_{3}=\operatorname{Max} \sum_{k=1}^{i k}\left(T S_{i 0}^{k}-T F_{i 0}^{k}\right)-\operatorname{Min} \sum_{k=1}^{i k}\left(T S_{i 0}^{k}-T F_{i 0}^{k}\right)
\end{aligned}
$$

$\operatorname{Min} f_{4}=\sum_{i=1}^{I} i k$

According to the task requirements and survey ship performance parameters, determine the constraints on the survey ship scheduling model: a survey ship is scheduled to arrive at the sea after debugging preparation time constraints, the second is the measurement of ship sailing time constraints, and the third is the longest survey ship sailing time constraints, and the fourth is the survey ship to complete the task back to the base of the maintenance time $D R$ constraint, which are:

$$
\left\{\begin{array}{l}
T S_{i j}<M B T_{i j}-D T_{i} \\
T S_{i j}-T F_{i j-1}>L\left(M_{i j-1}, M_{i j}\right) / V_{i} \\
T S_{i 0}-T F_{i 0}<D M A X \\
T F_{i 0}^{k+1}>T S_{i 0}^{k}+D R
\end{array}\right.
$$

In type (5), $M B T_{i j}$ is the duration of point $M_{i j}, V_{i}$ is the average speed of boat $\mathrm{i}, D M A X$ is the survey ship's longest single time at sea. In the case of stopping foreign port situation, a virtual point $M_{f_{n}}$ can be adding to the schedule plan and turn the $T F_{i 0}$ to the time $T F_{i f_{n}}$ when the boat leave. 


\section{Scheduling Algorithm}

In the astronautic survey ship scheduling problem, space launch time of tasks survey ship time measurement, sea and whether to limit the measurement ship types are known, the algorithm needs a measurement ship per scheduling dispatch plan.

The input variable is the measurement of the ship 's annual survey mission plan $M P_{t}$.

$$
M P_{t}=(M, M T B, M T F, R, S, B)
$$

$\mathrm{M}$ means the measure point, MTB means the start time of the point, MTF is the end time, $\mathrm{R}$ references the rocket, $\mathrm{S}$ is the satellite and $\mathrm{B}$ is the boat. The output scheduling scheme is the sum of the scheduling schemes for each of the sea survey ships.

$$
B P_{i}^{k}=\left(M_{0}, T S_{i 0}^{k}\right),\left(M_{i 1}, T S_{i 1}^{k}, T F_{i 1}^{k}\right), \ldots,\left(M_{i j}, T S_{i j}^{k}, T F_{i j}^{k}\right), \ldots,\left(M_{i n k}, T S_{i n k}^{k}, T F_{i n k}^{k}\right),\left(M_{0}, T F_{i 0}^{k}\right)
$$

Each of schedule plan contains three parts, which are the measure point, the arrive time and the leave time.

Survey ship in scheduling tasks, due to the measurement process in too many constraints, heuristic algorithm is employed to obtain the infeasible solutions more, so the use of randomly generated feasible annual scheduling scheme, the algorithm flow as follow:

Step1 Randomly sent a free survey ship.

Step2 To determine whether all the tasks have been completed: yes- Output feasible annual survey ship scheduling scheme, no-To step3.

Step3 Put points which ships can reach, the first point of base and foreign port into the random selection $R$, then choose one point $M_{j}$ randomly from $R$. Then the measurement ship's position, status update to the completion of the measuring point. Determine whether $M_{j}$ is a base: yes-To step1, no-To step2.

Random selection of the measurement points in the collection of $\mathrm{R}$ can be reached, and the measurement of the ship's supply can ensure that the ship can return to the base from the point of measurement.

The comprehensive evaluation of the four targets is needed in the formation of the annual scheduling plan. In this paper, the weighted method is used to evaluate the annual scheduling scheme, that is, the objective function is normalized, and the original function is divided by the maximum value of the function, and the new objective function $f_{i}{ }^{\prime}$ is obtained. The weighted coefficient $\lambda_{i}$ of each objective function is determined by the decision maker of the scheduling scheme.

$$
f=\sum_{i=1}^{4} f_{i} * \lambda_{i}
$$

In all of the randomly generated solutions, the weighted objective function values are selected by the five different schemes, and then the final scheme is selected.

The author also designed a relatively simple and fast algorithm to generate a satisfactory solution. the algorithm flow as follow:

Step1 Send the available ship which has the current shortest time at sea of the year.

Step2 To determine whether all the tasks have been completed: yes- Output feasible annual survey ship scheduling scheme, no-To step3.

Step3 The scheduling is added to the time sequence of feasible nearest task points.

Step4 To reach the point of measurement can meet the navigation time constraints: yes-To step5, no-Put that point back and back to step2.

Step5 Judge whether the measure can meet the back base constraints after the completion of the measurement task: yes-Back to step2, no-To step6.

Step6 Determine the survey ship could reach the foreign port nearby: yes-To step7, no- Survey ship to return to base and back to step1.

Step7 Judge whether cost more than the boat docked port back to base and send another boat: yes-Stop at the foreign port and back to step2, no-Back to base and roll back to step1. 
This algorithm add the objectives and constraints into every step of the algorithm, such as dispatch boat in both annual sea time equilibrium, consider every ship in single at sea as far as possible complete test task such as, algorithm efficiency compared with the previous algorithm has very big promotion.

\section{Experiment}

In this section, we will carry out the algorithm of the previous algorithm, and calculate the case data, and get the relative satisfaction of the space launch maritime survey ship scheduling scheme. If a year's space launch plan is shown in the following table:

Table 1 The annual space launch plan and the corresponding measurement point information

\begin{tabular}{cccccc}
\hline No. & Task number & Launch time & Measurement duration & Point position & Boat form requirements \\
\hline 1 & A-02 & $02-18$ & 2 & $(157,25)$ & Null \\
2 & A-04 & $03-29$ & 2 & $(-168,40)$ & Null \\
3 & A-05 & $05-10$ & 2 & $(-158,22)$ & Null \\
4 & A-06 & $05-01$ & 2 & $(-168,6)$ & Null \\
5 & A-07 & $06-05$ & 2 & $(150,-8)$ & Null \\
6 & A-08 & $08-14$ & 2 & $(170,-4)$ & Null \\
7 & A-09 & $09-07$ & 2 & $(152,15)$ & Null \\
8 & A-10 & $09-29$ & 2 & $(-174,14)$ & Null \\
9 & A-11 & $11-14$ & 2 & $(139,-3)$ & Null \\
10 & A-12 & $11-14$ & 10 & $(100,11)$ & Null \\
\hline
\end{tabular}

Table 2 Basic information of ship

\begin{tabular}{ccccccc}
\hline No. & Name & Prepare time & Sailing speed & Rest time & Cost & Max time in sea \\
\hline 1 & & 2 & 400 & 20 & 10 & 60 \\
2 & X-01 & 2 & 400 & 20 & 10 & 60 \\
3 & X-02 & 2 & 400 & 20 & 10 & 60 \\
& X-03 & & & & & \\
\hline
\end{tabular}

Then use the second algorithm to calculate the satisfactory solution which is shown as follow: 
Table 3 Annual scheduling scheme for survey ship

\begin{tabular}{cccccc}
\hline No. & Boat & Start position & Start time & Arrive position & Arrive time \\
\hline 1 & X-01 & Base & $02-05$ & A-02 & $02-16$ \\
2 & X-02 & Base & $03-08$ & A-04 & $03-27$ \\
3 & X-01 & Base & $04-14$ & A-05 & $05-08$ \\
4 & X-03 & Base & $04-06$ & A-06 & $04-29$ \\
5 & X-02 & Base & $05-18$ & A-07 & $06-03$ \\
6 & X-03 & Base & $07-24$ & A-08 & $08-12$ \\
7 & X-03 & A-08 & $08-16$ & A-09 & $09-05$ \\
8 & X-01 & Base & $09-07$ & A-10 & $09-27$ \\
9 & X-02 & Base & $10-31$ & A-11 & $11-12$ \\
10 & X-03 & Base & $10-31$ & A-12 & $11-12$ \\
11 & X-03 & A-06 & $05-03$ & Base & $05-26$ \\
12 & X-03 & A-09 & $09-09$ & Base & $09-20$ \\
13 & X-03 & A-12 & $11-24$ & Base & $12-06$ \\
14 & X-02 & A-04 & $03-31$ & Base & $04-19$ \\
15 & X-02 & A-07 & $06-07$ & Base & $06-23$ \\
16 & X-02 & A-11 & $11-16$ & Base & $11-28$ \\
17 & X-01 & A-02 & $02-20$ & Base & $03-02$ \\
18 & X-01 & A-05 & $05-12$ & Base & $06-05$ \\
19 & X-01 & A-10 & $10-01$ & Base & $10-21$ \\
\hline
\end{tabular}

\section{Summary}

In this paper, we analyze and study the mission of the space launch survey, determine the target of the space launch of the sea survey scheduling task, that is, the definition of the scheduling problem and the scheduling scheme. The analysis of all aspects of the marine survey, clear every aspect of the goals and tasks defined to build an aerospace launch a conceptual model of the marine surveying task scheduling problem, carries on the science reasonable and clear description. A mathematical model of the scientific and reasonable space launch maritime survey scheduling problem is established, which is the goal, the constraint condition and the scheduling rule. Starting from the actual demand as far as possible mining scheduling goal. We know that this is the multi-objective problem, which is a key step in the modeling; constraints by measuring ship its constraints, measurement base ship security constraints, sailing on the sea and the execution task constraints considered, which is modeling is an important part of the scheduling rules is survey ship in a certain position, how to select the appropriate target criterion from the feasible multiple moving location is the key to ensure the orderly scheduling reasonable.

\section{References}

[1] Wang S. China's Space Instrumentation Ship,Yuan Wang[J]. China Aerospace, 1994.

[2] Wang Y, Wang S, Cao H, et al. Research on TT\&C Information Exchange Model of Space Instrumentation Ships for TT\&C IP Network[J]. Journal of Spacecraft Tt \& C Technology, 2011.

[3] YANG Yi-fei,XIE Yong(Satellite Maritime Tracking \& Controlling Department of China,Jiangyin 214431,China);Generation Method of Space Target Orbit Through Shipbome TT\&C Radar Simulation [J];Telecommunication Engineering;2008-09.

[4] YANG Lei, WU Meng-da, ZHANG Zhong-hua. Forecasting For Non-Stationary Errors Of Ship-Measured Data Based On Wavelet[J]. Systems Engineering and selectronics, 2009, 31:930-933.

[5] Xue G, Xiaoyong L I, Zhang Z, et al. Fusion Algorithm for Multi-source Tracking Data of Space Instrumentation Ship[J]. Journal of Spacecraft Tt \& C Technology, 2011. 